\title{
ALAT BANTU PENDINGINAN FILTER OLI MOBIL
}

\author{
Taufiq Hidayat $^{1}$
}

\begin{abstract}
ABSTRAK
The main function of an oil filter in a car is to filter the oil coming from the charter to be circulated to the engine. The main function of the oil between it is as a lubricant and engine coolant. The engine working temperature is affected by the engine cooling system and the oil function which acts as a cooler. One effort to improve the quality of oil cooling can be done with the addition of cooling aids placed in the oil filter. The purpose of this research is to determine the effectiveness of changes in the working temperature of the engine mounted cooling aids on oil filters. The method used to conduct research is the use of metal and aluminum based tools with the number of fins that are varied. The shape of the tool is a metal sleeve with fin fins that vary in number. The results of the temperature scale under the influence of engine speed in this study is the greatest level of decline with variations in the number of fins of $10^{\circ} \mathrm{C}$. Whereas with the use of different materials, a $50 \mathrm{oC}$ reduction was obtained in the use of aluminum compared to stainless steels.
\end{abstract}

Keywords: Engine Temperature, Oil Temperature, Assistive Devices, Rpm

\section{PENDAHULUAN}

Keberadaan oli di kendaraan mesin baik mesin pada sepeda motor maupun mobil sangatlah fital. Ada beberapa fungsi utama keberadaan oli, antara lain sebagai pelumas, pendingin, pembersih dan mencegah karat. Hasil pembakaran yang berupa panas hanya sekitar 25\% yang dimanfaatkan untuk kerja dan selebihnya masuk dalam katagori rugi panas yaitu effective work (25\%), friction loss (6\%), pumping loss (3\%), cooling loss (32\%), exhaust gass loss (34\%) (Helmi, 2012). Berdasarkan neraca panas di atas maka fungsi pendinginan pada motor menjadi penting, karena panas yang akan terserap oleh sistem pendinginan mencapai 32 persen. Panas yang berlebihan adalah salah satu penyebab berubahnya sifat-sifat mekanis serta bentuk dari komponen mesin. Sifat serta komponen

\footnotetext{
${ }^{1}$ Teknik Mesin, Universitas Nahdlatul Ulama Surakarta

*Corresponding author:

e-mail: viqdmangan@yahoo.co.id
} 
mesin bila telah berubah akan menyebabkan kinerja mesin terganggu dan mengurangi usia mesin (Maleev,1982).

Proses pendinginan yang dilakukan oleh mesin mobil adalah termasuk dalam sistem pendinginan paksa. Sistem pendinginan paksa dapat digambarkan adalah fluida yang berasal dari mesin (water jacket) menuju radiator menuju out put saluran menuju pompa air dan kembali masuk ke water jacket. Proses pendinginan juga bisa dilakukan dengan pengoptimalan fungsi oli sebagai pendingin. Langkah yang sudah diterapkan adalah pendinginan oli dengan mempergunakan oil cooler. Pada dasarnya penggunaan oil cooler adalah untuk menjaga kualitas oli tetap terjaga pada beban kerja suhu tinggi dan lama umur pakai oli bisa bertambah. Selain menjaga kualitas dan umur pakai maka pendinginan oil juga mampu membantu proses pendinginan mesin (Heywood, 1976). Cara lain yang bisa dilakukan untuk proses pendinginan adalah pengembangan proses pendinginan pada filter oli.

Funsi sirip pada selubung filter oli luar adalah memperluas luas permukaan yang menjadi sarana proses perpindahan panas. Suhu oli yang terlalu tinggi menyebabkan berkurangnya jumlah oli di carter karena penguapan. Suhu oli sebagai fungsi pendingin ikut mempengaruhi agar suhu kerja mesin terjaga pada suhu $80-90^{\circ} \mathrm{C}$ (Setyawan.dkk, 2015). Beberapa kajian penggunaan sirip dengan tujuan untuk proses perpindahan panas dengan mempergunakan tipe sirip radial (rectangular profile) dilakukan oleh Jubear A.J and Ali A. F. A. (2015) dengan tema efek tinggi sirip terhadap proses perpindahan panas konveksi. Hasil dari penelitiannya dapat disimpulkan bahwa dengan naiknya tinggi sirip dari $10 \mathrm{~mm}$ ke 45 $\mathrm{mm}$ koefisien konveksi turun $44 \%$ dan perbedaan suhu turun $41 \%$. Bentuk profil sirip yang berupa persegi panjang dengan menggunakan pendekatan FEM, dapat disimpulkan pemakain soft ware FEM untuk mendesain sirip persegi panjang mampu didesain dengan mudah dan pemilihan bahan mampu dipilih dengan mudah pula (Khrisna, et.all, 2014). Sumber panas pada filter oli mesin berasal dari panas oli yang mengalir. Kecepatan aliran oli bisa berpengaruh terhadap besaran tinggi suhu oli, hal ini sesuai dengan yang disampaikan oleh Wibowo A.K dan Dwiyantoro B.A (2014). Penggunaan simulasi didapatkan hasil lube oil cooler yang dipasang seri dan paralel berdampak pada cooling capasity lube oil cooler. Dari hasil simulasi, susunan cooler seri menghasilkan cooling capacity yang lebih baik dari pada susunan cooler paralel pada kapasitas lube oil yang sama. Hal tersebut terjadi karena flow ratio lube oil untuk masing-masing tube pada susunan cooler seri lebih seragam dari pada susunan cooler paralel. Keseragaman flow rate pada masing-masing tube ditunjukkan dengan kecilnya standard deviasi flow ratio. Kapasitas 50 gpm memiliki standard deviasi flow ratio sebesar 0,46 untuk susunan seri dan 0,75 untuk susunan paralel. Semakin besar kapasitas lube 
oil maka distribusi flow rate pada masing-masing tube semakin tidak seragam. Selain itu susunan cooler seri memiliki pressure drop yang lebih besar dari pada susunan cooler paralel. Pemasangan susunan cooler dengan kapasitas 30 gpm memiliki tingkat keseragaman yang paling tinggi ditunjukkan dengan standard deviasi flow ratio pada masing-masing tube yang paling kecil sebesar 0,33 (Wibowo A.K dan Dwiyantoro B.A,, 2014).

Tingginya suhu kerja mesin dipengaruhi oeh proses pendinginan yang dilakukan oleh sistem pendinginan paksa dengan fluida air. Faktor lain adalah pendinginan yang dilakukan oleh oil pelumas. Penempatan oil cooler pada proses pendinginan oli berdampak pada suhu kerja mesin, sehingga performace mesinpun akan mengalami perubahan khususnya suhu mesin dan konsumsi bahan bakar. Penggunaan oil cooler juga harus didasarkan pada dampaknya, apakah akan berakibat turunnya suhu kerja yang dibawah suhu kerja mesin atau tidak. Aris Ansori melakukan penelitian terhadap penggunaan oil cooler pada proses pendinginan oli dan performance mesin. Analisa data menggunakan metode deskriptif. Berdasarkan pengujian, Oil cooler bekerja efektif saat putaran mesin $7000 \mathrm{rpm}$ karena mampu menurunkan suhu oli mesin hingga $13^{\circ} \mathrm{C}$, namun torsi mengalami penurunan sebesar $0,43 \%$, daya mengalami penurunan sebesar $1,22 \%$. Tekanan efektif rata-rata mengalami penurunan sebesar 1,15\%. konsumsi bahan bakar mengalami kenaikan sebesar 5,34 \%. Senada dengan Setefanus A.B.S dan Ansori A (2017), Roberto, et. all, (2015) dari hasil penelitiannya juga menyimpulkan penggunaan oil cooler berdampak pada perlambatan kenaikan suhu oli. Dampak dari kondisi suhu oli akan mempengaruhi dari suhu kerja mesin (Safayet, et.all, 2015).

Selain penggunaan oil cooler, performa oli pelumas juga bisa dikondisikan dengan pengunaan oli pelumas yang berasal dari nabati K.S.V. Krishna reddy juga melakukan penelitian dengan tema penggantian oli berbahan dasar minyak mineral dengan minyak nabati yang ramah lingkungan. Kesimpulan dari penelitian ini adalah merekomendasikan minyak nabati bisa dijadikan bahan dasar pelumas. Pemilihan minyak nabati harus disesuaikan dengan nilai properties oli antara lain nilai flast poinnya, pour pointnya dan sifat pelumasnya. Sebagai gambaran perbandingan nilai propertiesnya, sperti tampak pada Tabel 1 (Heywood, 1988).

Vinod et. all (2017) juga melakukan penelitian mengganri oil standart pabrik dengan oli yang berasal dari coconut oil dan hasilnya menunjukkan adanya penuruhan emisi dan pemakaian bahan bakar. 
Tabel 1. Physical Characteristics of SAE 20 W40 and Palm Oil

\begin{tabular}{|c|c|c|}
\hline Typical properties & $S A E 20 W 40$ & Palm Oil \\
\hline Specific gravity@20 $20^{\circ}$ & 0.855 & 0.865 \\
\hline Kinematic viscosity,cSt@40 $40^{\circ} \mathrm{C}$ & 120 & 40.24 \\
\hline Kinematic viscosity, cSt@100 10 & $14-16$ & 7.89 \\
\hline Viscosity index & 110 & 188 \\
\hline Flash point, ${ }^{\circ} \mathrm{C}$ & 220 & 280 \\
\hline Pour point, ${ }^{\circ} \mathrm{C}$ & -21 & 9 \\
\hline
\end{tabular}

\section{METODOLOGI}

Penelitian dengan populasi mobil rover, sampel pemasangan sirip pada oli luar dan variabel bebas jumlah sirip dan bahan sirip dan rpm. Sedangkan variabel terikat adalah suhu pada titik titik tertentu. Adapun desain alat bantu pendingin bersirip dan pemasangan pada filter oli luar engine bermotor dapat dilihat pada Gambar 1, 2 dan 3.

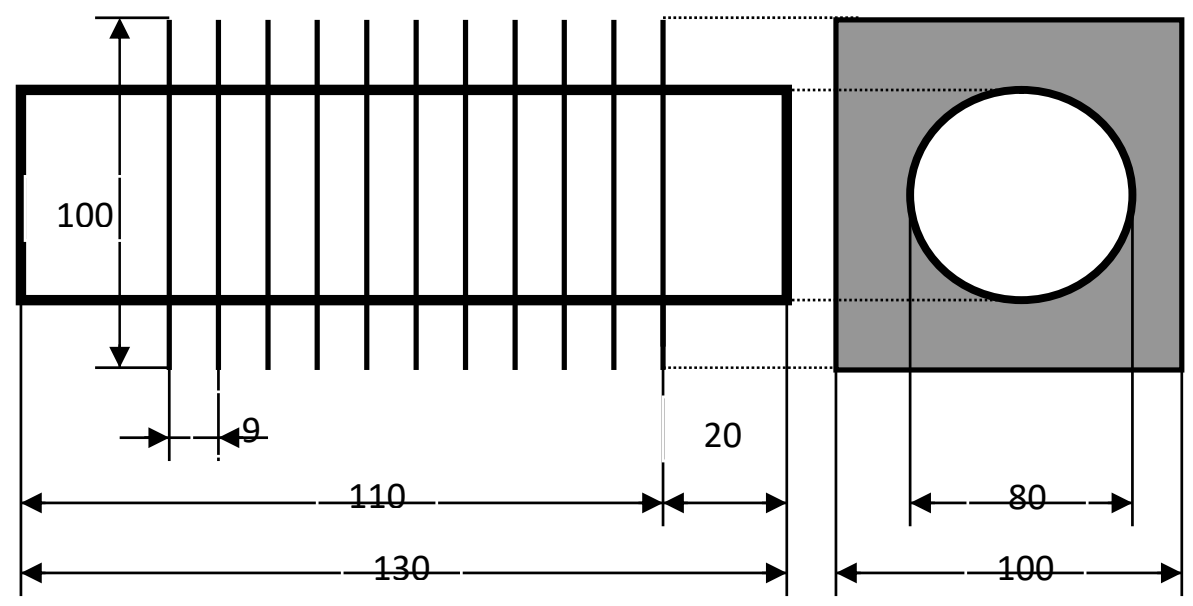

Gambar 1. Konstrulsi Alat Bantu dengan 11 Sirip

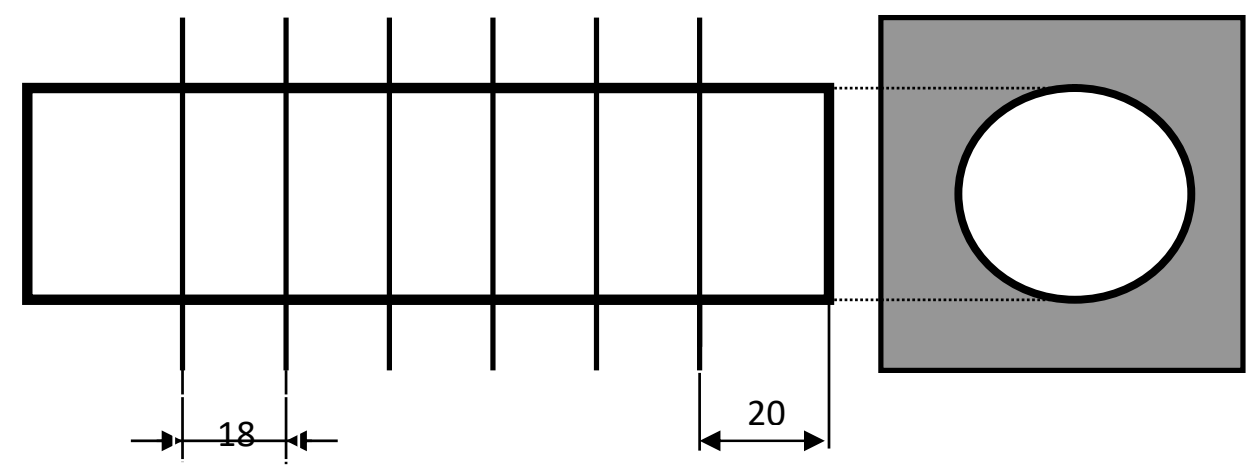

Gambar 2. Konstrulsi Alat Bantu dengan 6 Sirip 


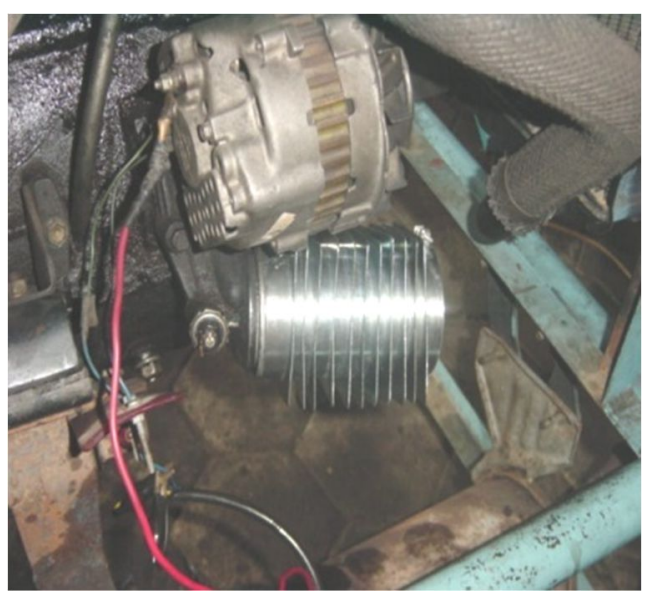

Gambar 3. Penempatan Alat Bantu Pendingin di Filter Oli

Diskripsi pelaksanaan penelitian dapat dijelaskan dengan specifikasi penggunaan bahan penelitian dan titik titik penganbilan suhu adalah seperti tampak pada Tabel 2 dan 3 . Alat ukur yang dipergunakan adalah thermo couple.

Tabel 2. Specifikasi Bahan Penelitian

\begin{tabular}{|c|c|c|c|c|c|}
\hline \multirow[t]{2}{*}{ Jumlah Sirip } & \multirow{2}{*}{\multicolumn{2}{|c|}{ Bahan }} & \multicolumn{3}{|c|}{ Spec Sirip } \\
\hline & & & Ukuran sirip (mm) & Silinder (mm) & Jarak Sirip (mm) \\
\hline Sirip 11 & Steinless steel & $\mathrm{Al}$ & $100 \times 100 \times 0.25$ & L 130 & 5 \\
\hline Sirip 6 & & & & & 18 \\
\hline
\end{tabular}

Tabel 3. Titik Titik Tempat Pengambilan Data

\begin{tabular}{|c|c|c|c|}
\hline T1 & $\mathbf{T 2}$ & T3 & T4 \\
\hline Switch oli & Pipa selongsong & Badan sirip & Suhu air pra radiator \\
\hline
\end{tabular}

\section{HASIL DAN PEMBAHASAN}

\section{Filter Oli Luar}

Pembahasan dalam proses pendinginan filter oli dengan mempergunakan sirip maka perlu dipahami dahulu konstruksi dan aliran oli. Filter oli dapat dibedakan menjadi dua model, yaitu filter oli model cartridge fit-in dan model cartridge spin-on. Cartidge spin-on adalah model filter oli yang paling banyak dipergunakan. Konsruksi dari filter seperti pada Gambar 4. 


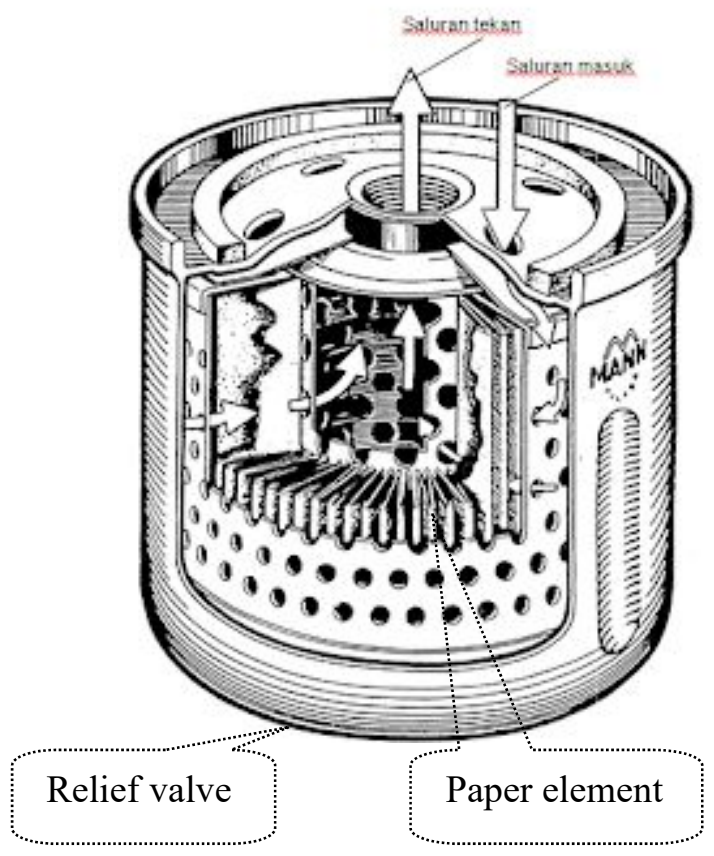

Gambar 4. Filter oli

Oli yang berasal dari carter masuk melewati lubang yang mengelilingi satu saluran yang ada ditengah dan merupakan saluran keluar. Oli yang mempunyai suhu bersentuhan dengan dinding filter dan terjadi proses perpindahan panas kondukksi, perpindahan panas secara konduksi didinding filter diteruskan dengan perluasan ares pendinginan dengan mempergunakan sirip yang portabel dalam pemasangan di bodi filter oli. Suhu awal oli terdeteksi melalui swicth oli. Suhu pada putaran 2200 mencapai $95^{\circ} \mathrm{C}$. Engine yang dpergunakan dalam penelitian ini adalah engine stand bensin L 300. Adapun specifikasi dari engine L300 adalah seperti pada Tabel 4.

Tabel 4. Specifikasi Mitsubishi Colt L300 Bensin

\begin{tabular}{|c|c|}
\hline Jenis & : Pick up \\
\hline Engine & : G33Satum SOHC 1400cc \\
\hline Bore x stroke & : $74.5 \mathrm{~mm} \times 86 \mathrm{~mm}(4 \mathrm{G} 331400 \mathrm{cc})$ \\
\hline Sistem bahan bakar & : Karburator \\
\hline Transmisi & : Manual 5 speed \\
\hline
\end{tabular}

Bahan sirip adalah stainless steels dan aluminium sedangkan selongsongnya adalah stainless steels. Properties bahan stainless steel dan aluminium dapat dilihat pada Tabel 5. Perluasan area sarana pendingin dengan jumlah sirip 6 adalah sebesar $29.856 \mathrm{~mm}^{2}$ dan sirip dengan jumlah 11 sebesar $54736 \mathrm{~mm}^{2}$. 
Tabel 5. Konduktivitas Termal Bahan

\begin{tabular}{lll}
\hline Bahan & $\mathbf{K}\left(\mathbf{W} / \mathbf{m}^{\mathbf{0}} \mathbf{K}\right)$ \\
\hline Aluminium & $:$ & 237 \\
\hline Baja stainless & $:$ & 14 \\
\hline Besi & $:$ & 79.5 \\
\hline Emas & $:$ & 314 \\
\hline Intan & $:$ & 2000 \\
\hline Tembaga & $:$ & 390 \\
\hline Kuningan & 151 \\
\hline
\end{tabular}

\section{Efektifitas Pemakaian Bahan Sirip Terhadap Penurunan Suhu Oli (Ruang Cylinder Head)}

Pada gambar 7 bahwa pemakaian sirip yang jumlahnya semakin banyak mampu menurunkan suhu oli semakin besar yang diukur pada oli di ruang kepala silinder. Pemakaian jumlah sirip sebelas dibndingkan dengan pemakian sirip enam terpaut $5^{\circ} \mathrm{C}$ sedangkan dibandingkan dengan tidak mempergunakan sirip terjadi perbedaan lebih besar. Sebelas sirip terjadi penurunan $5-15^{\circ} \mathrm{C}$ dan dengan enam sirip terjadi penurunan $5^{\circ} \mathrm{C}-10^{\circ} \mathrm{C}$. Penggunaan jenis bahan berdampak pada penurunan suhu rata rata yaitu dengan mempergunakan sirip aluminium terjadi perbedaan $5^{\circ} \mathrm{C}$ dibandingkan dari stainless steels. Nilai kondukriviras bahan sangat mempengaruhi. Semakin besar maka nilai kalor yang ditransver juga meningkat pengaruh lainnya adalah luas permukaan dan tebal tipis bahan sirip. Dari gambar juga memperlihatkan garis linear, semakin tinggi rpm maka suhu juga semakin meningkat hal ini disebabkan beban mesin yang semakin besar dan proses pembakaran yang menghasilkan suhu maksimal pembakaran semakin tinggi pula.

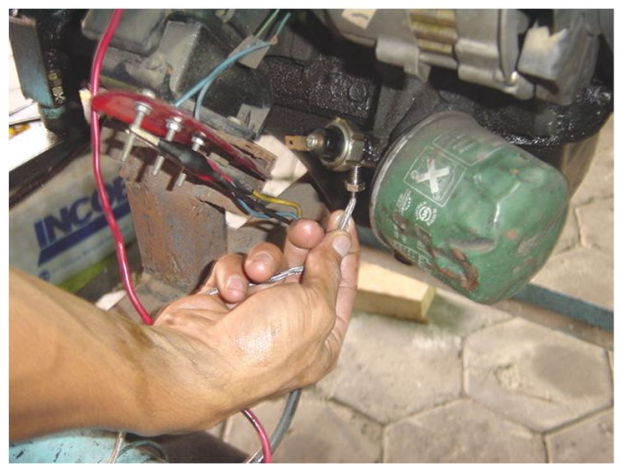

Gambar 5 Pengukuran Suhu Oli di Switch Oli

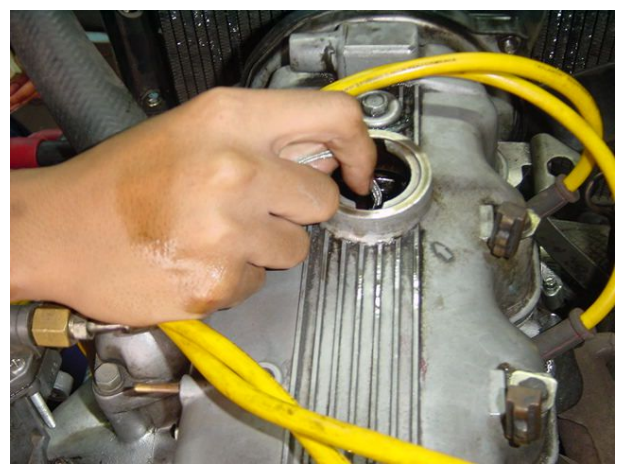

Gambar 6 Pengukuran Suhu Oli di C. Head 


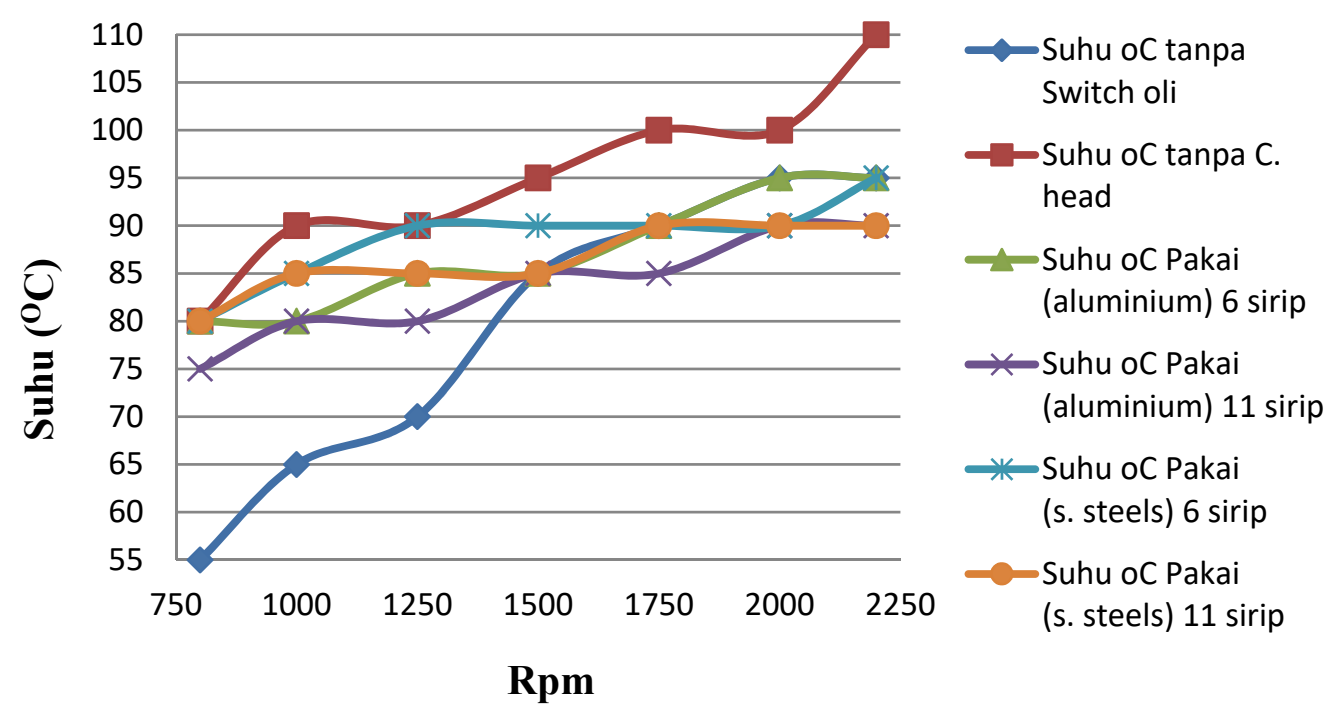

Gambar 7. Hubungan Rpm dan Suhu Oli Pada Kepala Silinder

Gambaran garis linear pada suhu yang diukur pada ruang kepala silinder sebelum memakai filter oli dengan persamaan $y=0,017 x+68.86$ dan garis regresi $\mathrm{r}^{2}=0.920$ sedangkan pada 11 sirip dengan bahan aluminium $y=0.006 x+76.38$ dan $r^{2}=0.84$. Semakin tinggi rpm maka penurunan suhu dengan penggunaan bahan sirip dari aluminium dan sainless steels cenderung sama seperti pada rpm 2200 pada sirip 6 dan 11 pada di kedua bahan sama yaitu $95^{\circ} \mathrm{C}$ dan pada 11 sirip suhu $90^{\circ} \mathrm{C}$. Kondisi ini tidak dipengaruhi oleh laju perpindahan panas akan tetapi konstruksi dari sirip yang di setting tidak permanen pada selongsong. Laju perpindahan panas akan sangat dipengaruhi oleh nilai konduktifiras dari bahan.

\section{Efektifitas Memakai Dan Tanpa Sirip Terhadap Suhu Mesin}

Gambar 9 menunjukkan penambahan perluasan dari $29.856 \mathrm{~mm}^{2}$ pada jumlah sirip 6 dan $54736 \mathrm{~mm}^{2}$ pada sirip 11 terjadi penurunan suhu mesin yang di ambil dari suhu air sebelum masuk ke radiator. Penurunan berhubungan lurus dengan jumlah sirip yang dipakai semakin jumlah sirip lebih besar berdampak turunnya suhu air dari $95^{\circ} \mathrm{C}$ (tanpa pendingin) menjadi $85^{\circ} \mathrm{C}$ (sirip 6) dan $80^{\circ} \mathrm{C}$ (11 sirip). Suhu mesin masih dalam suhu mesin normal.

Hal ini juga sesuai yang disampaikan oleh Agista Bagus Saputra dan Aris Ansori bahwa dengan bantuan oil cooler terjadi penurunan suhu dan berdampak suhu mesin menjadi dibawah suhu kerja mesin dan kondisi ini berdampak juga pada turunnya hp dan ...mesin sekaligus meningkatkan pemakaian bahan bakar. Pada penggunaan sirip dengan bahan dari sainless steels mengalami penuruan dari $95^{\circ} \mathrm{C}$ (tanpa penggunaan sirip) turun menjadi $90^{\circ} \mathrm{C}$ 
(sirip 6) dan $85^{\circ} \mathrm{C}$ (sirip 11). Selisih penurunan adalah $10^{\circ} \mathrm{C}$. Besar luas area dan nilai konduktifitas bahan sangat berpengaruh terhadap pelepasan energi lewat sirip.

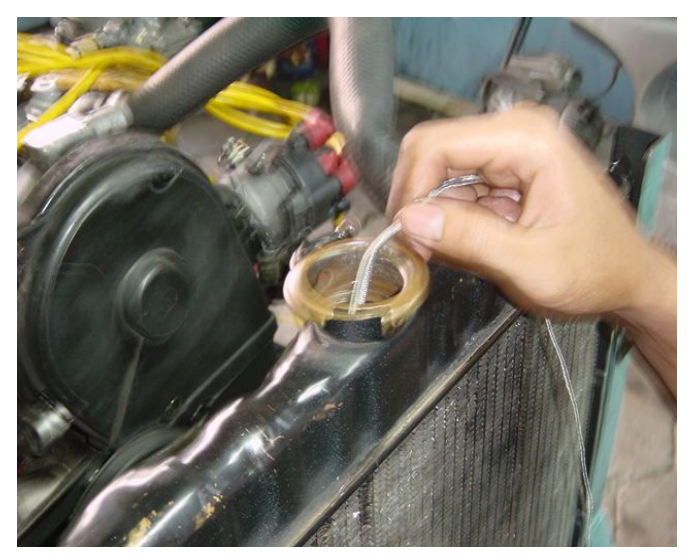

Gambar 8 pengukuran suhu mesin pada radiator

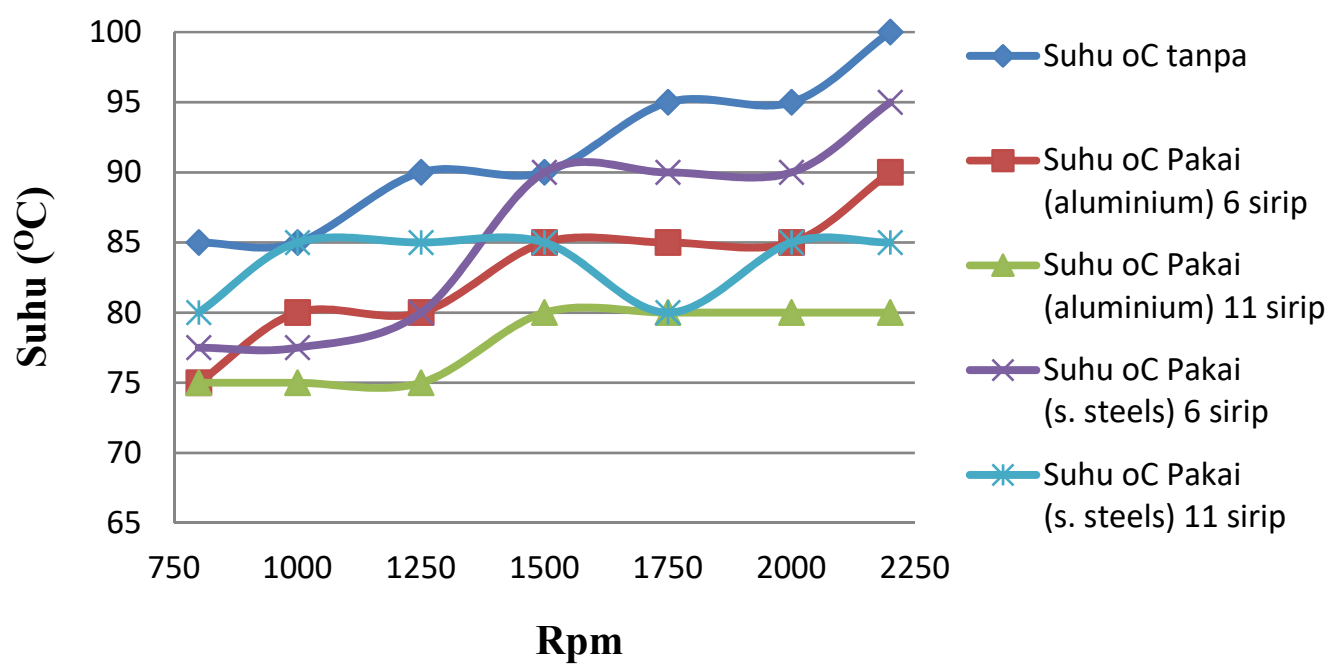

Gambar 9 Hubungan Rpm Dengan Suhu Mesin (Ruang Radiator)

Fungsi sekunder oli yang berfunsi sebagai pendingin akan meningkar prisentasenya sehingga serapan panas yang dihasilkan dari proses pembakaran juga meningkat. Penurunan suhu kerja mesin, apabila dibawah suhu kerja mesin akan berdapak terhadap kualitas pembakaran. Suhu awal pembakaran akan mempengaruhi oleh suhu akhir pembakaran. Suhu awal pembakaran berasal dari suhu internal yaitu suhu mesin akibat proses pembakaran dan suhu eksternak yaitu suhu dari kondisi suhu atmosfir. Pengaruh penggunaan bahan yang mempunyai nilai konduktifitas bahan yang berbeda semakin besar nilai k maka kalor yang di 
transver akan semakin besar. Efektifitas penggunaan pendinginan sirip ini sangat di pengaruhi oleh jenis oli yang dipergunakan.

\section{Oli Dan Suhu Mesin}

Pemakaian filter oli juga perlu memperhatikan pemakaian jenis oli hubungannya dengan kekentalannya. Apabila kekentalan oli yang encer maka penurunan suhu mesin akan berdampak pada performance mesin. Suhu awal pembakaran akan terpengaruh dengan turunnya suhu mesin dibawah suhu mesin standart $80^{\circ} \mathrm{C}-90^{\circ} \mathrm{C}$.

\section{KESIMPULAN}

1. Semakin jumlah sirip meningkat maka luas bidang untuk perpindahan panas semakin luas pula dan jumlah pelepasan kalor juga meningkat. Proses pendinginan akan semakin baik yang mampu melakukan penurunan $\pm 10^{\circ} \mathrm{C}$.

2. Pemakaian bahan juga mampu mempengaruhi pelepasan kalor, semakin besar konduktifitas bahan maka proses penurunan suhu juga akan lebih baik. Dibandingkan stainless steels, aluminium mampu lebih besar derajat penurunannya $\pm 5^{\circ} \mathrm{C}$.

\section{DAFTAR PUSTAKA}

Jubear A.J and Ali A. F. A. 2015. The Effect Of Fin Height On Free Convection Heat Transfer From Rectangular Fin Array. International Journal of Recent Scientific Research Research. Vol. 6, Issue, 7, pp.5318-5323, July, 2015. ISSN: 0976-3031.

Wibowo A.K dan Dwiyantoro B.A, 2014. Studi Numerik Peningkatan Cooling Performance pada Lube Oil Cooler Gas Turbine yang Disusun Secara Seri dan Paralel dengan Variasi Kapasitas Aliran Lube Oil. JURNAL TEKNIK POMITS Vol. 3, No. 2, (2014) ISSN: 2301-9271.

Heywood, Jhon B 1988, Internal Combustion Engine Fundamentals, McGraw Hill Book Company.

Khrisna R.K.S.V., Naval Kabra, Umesh Kunchum, and T. Vijayakumar, 2014. Experimental Investigation on Usage of Palm Oil as a Lubricant to Substitute Mineral Oil in CI Engines. Chinese Journal of Engineering. Volume 2014, Article ID 643521, 5 pages.

Safayet H.M.D, Raiyan M.F, Sayeed, S.J.U. Ahamed, 2015, Analysis of Thermal Characteristics of Flared and Rectangular Fin Profiles by Using Finite Element Method. IOSR Journal of Mechanical and Civil Engineering (IOSR-JMCE) e-ISSN: 22781684,p-ISSN: 2320-334X, Volume 12, Issue 5 Ver. II (Sep. - Oct. 2015), PP 58-67.

Roberto C, Davide Di Battistaa, Marco Mauriello, 2015, Effects of Oil Warm Up Acceleration On The Fuel Consumption Of Reciprocating Internal Combustion Engines. ATI 2015 - 70th Conference of the ATI Engineering Association. Energy Procedia 82 ( 2015$) 1-8$. 
Setefanus A.B.S dan Ansori A, 2017, Pengaruh Pengaplikasian Oil Cooler Terhadap Suhu Oli Dan Peforma Mesin Pada Kendaraan Sepeda Motor Mega Pro Tahun 2011 JPTM. Volume 06 Nomor 02 Tahun 2017, 68 - 75

Setyawan, Kholis Nur dan Arsana, I Made. 2015. Pengaruh Temperatur Fluida Masuk Terhadap Kapasitas Oil Cooler pada Sistem Pelumasan Sepeda Motor Suzuki Satria 150 CC. Surabaya. Jurnal Tekni9k Mesin. Vol. 4, No 1 ,P.1-8.

Vinod K.M.S, Suresh R, Jegadeeswaran N 2017. International Journal of Advances in Scientific Research and Engineering (ijasre). Vol. 3. Special Issue 1, August-2017. EISSN : 2454-8006. 